\title{
Using the Portuguese version of the Bicultural Scale in Brazil
}

\author{
O uso da versão em português da Escala de Biculturalidade no Brasil
}

\author{
Carlos Zubaran, ${ }^{1,2,3}$ Katia Foresti, ${ }^{2,3}$ Karina Nunes Persch ${ }^{3}$
}

\begin{abstract}
Introduction: Brazil has received influxes of people, mainly from Africa, Europe and Japan, forming one of the most heterogeneous populations in the world. Some groups, particularly in Southern Brazil, have retained their original cultural traditions, whilst acquiring elements of the typical local Brazilian cultural identity. This is the first study designed to formally evaluate biculturality in Brazil.

Objective: To psychometrically assess and validate the Portuguese version of the Bicultural Scale (BS) in Brazil.

Methods: The BS was adapted and translated to Portuguese and tested for the first time in Brazil in a sample of descendants ( $n$ $=160$ ) from four immigrant groups and respective locations in Southern Brazil. A series of psychometric tests were conducted in order to examine the validity of the Portuguese version of the BS. Analyses of variance across scores for all subgroups were also conducted.

Results: Factor analysis revealed two main factors contributing to most of the variance in scores. The 10 items measuring affiliation with minority cultural characteristics and the typical Brazilian culture yielded Cronbach's alpha coefficients of 0.69 and 0.78 respectively, whereas the overall Cronbach's alpha for all 20 items of the BS was 0.67. There was a significant correlation between items related to the typical Brazilian culture and the generation since immigration of research participants $(r=0.23$, $p=0.004$ ). The mean time taken to complete the questionnaire was 7.4 minutes.

Conclusion: The results indicate that the Portuguese version of the BS is a valid, reliable and easy-to-use instrument to assess biculturality experienced by descendants of immigrants in southern Brazil. Keywords: Acculturation, emigration and immigration, questionnaires, bilingualism, Brazil.
\end{abstract}

\section{Resumo}

Introdução: O Brasil recebeu afluxo de imigrantes principalmente da África, Europa e Japão, formando uma das populações mais heterogêneas do mundo. Alguns grupos, particularmente no Sul do Brasil, têm mantido suas tradições culturais originais, ao mesmo tempo que adquirem elementos típicos da identidade cultural brasileira local. Este é o primeiro estudo a avaliar formalmente a biculturalidade no Brasil.

Objetivo: Avaliação psicométrica e validação da versão em português da Escala de Biculturalidade (EB) no Brasil.

Métodos: A EB foi adaptada e traduzida para o português e testada pela primeira vez no Brasil em uma amostra de descendentes de quatro grupos de imigrantes $(n=160)$ em diferentes localizações no Sul do Brasil. Uma série de testes psicométricos foram aplicados a fim de examinar a validade da versão em português da EB. Análises de variância através dos escores obtidos em cada subgrupo também foram conduzidas.

Resultados: A análise fatorial revelou que dois fatores principais contribuem para a maioria da variância nos escores. Os 10 items que medem afiliação com características culturais minoritárias e cultura típica brasileira demonstraram índice de Cronbach de 0,69 e 0,78 , respectivamente, enquanto que o alfa global de Cronbach para todos os 20 itens da EB foi de 0,67 . Houve correlação significativa entre os itens relacionados à cultura típica brasileira e a geração dos voluntários desde o período de imigração $(r=0,23$, $\mathrm{p}=0,004)$. O tempo médio para completar o questionário foi de 7,4 minutos.

Conclusões: Os resultados indicam que a versão em português da EB é um instrumento válido, confiável e de fácil utilização para avaliar expêriencias de biculturalidade de descendentes de imigrantes no Sul do Brasil.

Descritores: Aculturação, emigrações e imigração, questionários, bilinguismo, Brasil.

\footnotetext{
${ }^{1}$ School of Medicine, Western Sydney University, Sydney, Australia. ${ }^{2}$ Department of Psychiatry, Northern Sydney Local Health District, Sydney, Australia. ${ }^{3}$ Faculdade de Medicina, Universidade de Caxias do Sul (UCS), Caxias do Sul, RS, Brazil.

Financial support: none.

Submitted Sep 15 2015, accepted for publication Mar 07 2016. No conflicts of interest declared concerning the publication of this article.

Suggested citation: Zubaran C, Foresti K, Persch KN. Using the Portuguese version of the Bicultural Scale in Brazil. Trends Psychiatry Psychother. 2016;38(3):156-163. http://dx.doi.org/10.1590/2237-6089-2015-0050
} 


\section{Introduction}

Brazil was first opened to European influence in 1500, at which time it was inhabited by Amerindians. Since then, Brazil has received significant separate influxes of people, including Portuguese colonizers; African slaves; and later immigrants, mainly from Europe. ${ }^{1}$ As a result, Brazilians form one of the most heterogeneous populations in the world. ${ }^{2}$ European travelers described Brazil as a "festival of colors," whereas national intellectuals referred to it as "a society of crossed races." ${ }^{\prime 3}$ After independence from Portugal in 1822 , there was an emphasis on populating the southern region. From 1824, immigrants from Central Europe, mainly Germans, were settled in communities in river valleys not far from Porto Alegre, the provincial capital. ${ }^{4}$ Subsequently, in the last quarter of the 19th century, there was a significant influx of Italian immigrants, who settled in the mountainous regions of Rio Grande do Sul. After World War I, immigration from other countries, including Poland, took place. In the 1930s, immigration from Japan also became a significant phenomenon, accounting for almost one third of new arrivals to the country. ${ }^{4}$

Assessment of acculturation is a cornerstone of immigration research and examines the willingness of immigrants to embrace or reject elements of the host culture, thus producing varying degrees of bilingualism and biculturality. It is therefore paramount to take immigrants' viewpoints on their cultural adaptations into account in order to better understand the dynamic process of acculturation. Acculturation was initially conceived as the process through which immigrants and their descendants acquire the core values and prevailing attitudes of the host society. ${ }^{5}$ Considering the unprecedented scale of human migration, greater emphasis has been given to acculturation of migrants into host societies. ${ }^{6,7}$ Research has also developed in areas related to the obstacles and challenges faced by immigrants during their transitional journeys and eventual resettlement in new environments. ${ }^{8} \mathrm{~A}$ preliminary analysis of the extant research in the field of acculturation reveals a plausible association between acculturative stressors and mental disorders, including mood and anxiety disorders, as well as substance use, delinquent behavior, and suicidal tendencies. ${ }^{9-12}$

Previous studies have also explored new conceptual dimensions to understand the phenomenon of biculturality. ${ }^{13}$ Further understanding of migrants' bicultural identification may help clinicians to identify individuals' vulnerabilities and strengths. For example, studies developed to assess biculturality of Puerto Ricans living in the U.S. have indeed helped to clarify the role played by each cultural affiliation in increasing the risk for substance use and HIV infection. ${ }^{14}$ Research evidence in this area has also revealed that variable degrees of involvement with one's minority and majority cultural elements could also influence risk behaviors. ${ }^{15}$ Therefore, evaluation of biculturality is a pivotal step in the process of implementing interventions aimed at moderating risk factors for adverse events and promoting factors known to protect migrants from mental disorders including substance use. ${ }^{14}$

A range of research instruments have been developed to assess biculturality as well as the acculturation process experienced by immigrants and their descendants in host societies. It has been advocated that studies of biculturality should be modeled on a two-dimensional representation with independent scales measuring levels of cultural involvement with original and host society cultures. ${ }^{6}$ Moreover, acculturation scales that focus preponderantly on language mastery may produce inconsistent results. ${ }^{16}$ The Bicultural Scale (BS) was used initially to examine personal involvement in both Puerto Rican and American cultures and does not require mutual cultural exclusivity or focus exclusively on language usage, which is why it is generally considered a more comprehensive instrument for the assessment of acculturation. ${ }^{6}$

In this study, the authors report for the first time on the use of the BS in Brazil. A Portuguese version of this instrument, conceived to assess biculturality, was tested in a sample of descendants from immigrants living in cities considered cultural enclaves in Southern Brazil. This is to date the only Portuguese version of this particular instrument. It was hypothesized that the BS would constitute a reliable and valid assessment tool to assess biculturality. In this study, the hypothesis of potential differences in biculturalism among different minority cultural groups in Southern Brazil was also tested. To the authors knowledge this is the first time biculturality has been formally assessed via a quantitative approach in Brazil.

\section{Objectives}

The main objective of this study is to report on the preliminary field test of the Portuguese version of the BS in a sample of Brazilian volunteers from Southern Brazil. Research participants were interviewed in the towns of Nova Petrópolis, Nova Roma, Áurea and Ivoti, which are recognized ethnic enclaves of descendants of German, Italian, Polish and Japanese immigrants respectively. An additional objective in this study is to empirically evaluate the ease of use, internal structural consistency, 
reliability and validity of the Portuguese version of the BS.

\section{Methods}

\section{Sample recruitment}

This study comprised a convenience sample of 160 adult volunteers who were recruited at public health care outpatient facilities in the localities mentioned above. In this study, specific locations were considered as ethnic enclaves on the basis of information gathered from members of the respective ethnic groups, community folklore centers and a myriad of informal publications on immigration in southern Brazil. Recruitment occurred informally by word-of-mouth. Prospective participants who satisfied inclusion criteria were randomly invited to voluntarily enroll in the study. Inclusion criteria comprised regular use of German, Italian, Polish or Japanese languages at home or in the community as well as a significant bond to the ancestral culture, assessed through verbal confirmation. The main exclusion criterion was inability to understand the content of the scale and meaning of questions (e.g., limited command of Portuguese) as assessed by interviewers during a preliminary conference with potential participants aimed at explaining the research rationale.

\section{Informed consent}

This study was endorsed by the institutional Ethics and Research Committees of the Universidade de Caxias do Sul (UCS), which are the regulatory bodies supervising the scientific activities in the campuses of UCS (protocol no. CEP\#41). Trained bilingual interviewers explained the purpose of the study. All volunteers signed a consent form to indicate their voluntary agreement with all procedures involved in this project. Participants were informed that they could voluntarily terminate their participation in the study at any time with no consequences to themselves or to the quality of their health care. All information obtained from research volunteers was treated as confidential.

\section{The Bicultural Scale (BS)}

The BS has a two-dimensional structure with independent scales measuring levels of involvement with the minority immigrant and the majority society cultural values and traditions separately and it allows for different patterns of interaction between the cultural affiliations under investigation. ${ }^{6}$ Ten items representing core thematic acculturation categories were developed: One set of 10 items reflects the degree of affiliation with the minority culture and a parallel set of 10 items reflects the degree of cultural affiliation with the majority cultural elements. The two sets of 10 items are therefore equivalent, differing from each other only with respect to the cultural paradigms to which they refer. Items are formatted with a 4-point rating scale based on the frequency or strength of endorsement of a particular behavior, value, or belief, ranging from not at all (1) to very much (4).

\section{Translation and adaptation of the instrument}

The BS was translated into Portuguese taking into account semantic, idiomatic, experiential, cultural, and conceptual equivalence between the source and the target instruments. ${ }^{17,18}$ Two investigators proficient in both Portuguese and English developed the final Portuguese version of the BS. Each investigator performed the translations and adaptations in one direction, from one language to the other (translation and then back-translation). The final adapted version of the instrument was established by a multicultural committee of specialists who took into account both the translation and back-translation of the instrument. This committee consisted of professionals fully knowledgeable about the subject under investigation, many of whom were proficient in both languages.

A small number of adaptations were made to the original English version of the $\mathrm{BS}^{6}$ in order to adapt the instrument to both the minority and majority cultural affiliations investigated in this study. These changes were as follows:

1) The first 10 items describe affiliation with the original culture (German, Italian, Polish or Japanese cultures in this case). In the original English version the term "Puerto Rican" was used to indicate the cultural values of the specific minority group involved in the investigation of biculturality in the United States. In the Portuguese version of the BS used in Brazil, the adjectives "German," "Italian," "Polish," or "Japanese" were used instead.

2) In the original English version the word "American" was used to indicate the respective majority society cultural values and traditions involved in the process of biculturality. In the Portuguese version, the descriptors "typical Brazilian" or "typically Brazilian" were used instead.

3) The seventh item of each set of questions, which refers to enjoyment of TV programs aimed at 
the respondent's ethnic group in the original English version, was modified for the Portuguese version, which refers to "radio programs" instead. This is because of the widespread dissemination of this media in the region investigated, in contrast to a virtual non-existence of TV programs targeting minority group audiences in Southern Brazil.

4) The 10th item was modified from the original English scale by deleting the "all" when quantifying "friends" in the question that refers to the salience of one's children having friends from the same ethnic group.

Most of these adaptations have also been introduced in versions of the BS translated into and adapted for other languages. ${ }^{19}$ Three main broad themes comprising the scale appear to be clustered from the items mentioned above: language (items 4 and 6), values (items 1, 3, 5, 9 and 10) and entertainment and food (items 2, 7 and 8 ). The total score can vary in the range from 20 to 80.

\section{Scale administration and data management}

The study participants completed the questionnaires with minimal guidance from trained bilingual examiners, following standardized procedural instructions. The questions were read once, aloud and clearly, one-byone for each interviewee. All participants were initially instructed about how to complete the questionnaires following standardized information. The instructions were repeated until the participants acknowledged complete understanding of procedures. Specific questions not previously considered during initial instructions were answered on a one-by-one basis.

Pen-and-paper questionnaires were administered to the research participants. After the interviews had been completed, data from the questionnaires were transferred to a mainframe computer in the main research laboratory. Survey data were then converted to Microsoft Excel spreadsheets. Finally, visual accuracy checks were performed in order to confirm correct data recording. Satisfactory performance was defined as completion of all 20 questions included in each questionnaire.

\section{Statistical analysis}

Measures of central distribution and dispersion of data were calculated for all demographic characteristics. The usual procedures for estimating criterion-related validity of acculturation and biculturalism scales were followed in this study, including analyses of correlations between the scale's scores and measures such as respondents' generational status and scores computed as a result of identification with autochthonous values. ${ }^{20,21}$

The internal consistency of the Portuguese version of the BS was analyzed by generating Cronbach's alpha for each subset of questions in the assessment tool. A factorial analysis of the same scale was conducted by maximum likelihood factor analysis with Varimax rotation. The Scree Test was used to identify the most meaningful factor structure. Alpha coefficients were computed to estimate the internal consistency and reliability of the 10 -item scales measuring affiliation with either minority or majority cultural parameters.

Relevant analyses of correlations were performed between discrete variables of interest, which included correlations computed between the two sections of the BS. Additional parameters were analyzed, including ease of use (time taken to complete the BS and opinion about the level of the instrument's complexity) and test-retest reliability, the latter assessed by kappa coefficients generated between surveys conducted with an interval of 3-7 days. All statistical analyses were conducted using SPSS software.

\section{Results}

\section{Demographic data}

The overall mean age of the members of the sample was 46.19 years (standard deviation [SD] $=17.38$ ). Overall gender distribution was $110(68.8 \%)$ female to $50(31.3 \%)$ male participants. The sample distribution by post-migration generational status was as follows: 16 $(10 \%)$ participants were first-generation descendants, whereas $42(26.3 \%)$ and $102(63.7 \%)$ were secondgeneration and third-generation descendants to Brazil respectively. Table 1 shows figures for each cultural group.

\section{BS results}

The mean overall score (both subscales combined) for the BS was 42.01 ( $S D=6.29$; range $=35$ [27$62]$ ). The overall mean score for the subscale related to minority cultural factors was 21.8 ( $\mathrm{SD}=4.74$; range $=$ 32 [10-42]), whereas the score of the subscale related to typical Brazilian cultural aspects was 20.21 (SD = 4.37 ; range $=23[7-30])$. 
Table 1 - Demographic composition of the sample

\begin{tabular}{lccccc}
\hline & Overall & German & Italian & Polish & Japanese \\
\hline Mean age (SD) & $46.19(17.38)$ & $43.8(12.86)$ & $40.7(16.84)$ & $52.63(17.52)$ & $47.65(19.87)$ \\
Male & $50(31.3)$ & $8(20)$ & $9(22.5)$ & $18(45)$ & $15(37.5)$ \\
Female & $110(68.8)$ & $32(80)$ & $31(77.5)$ & $22(55)$ & $25(62.5)$ \\
First generation & $16(10)$ & - & - & $1(2.5)$ & $15(37.5)$ \\
Second generation & $42(26.3)$ & - & $11(27.5)$ & $11(27.5)$ & $20(50)$ \\
Third generation & $102(63.7)$ & $40(100)$ & $29(72.5)$ & $28(70)$ & $5(12.5)$ \\
\hline
\end{tabular}

Data presented as $\mathrm{n}(\%)$, unless otherwise specified.

$\mathrm{SD}=$ standard deviation.

\section{Factor analysis}

Maximum likelihood factor analysis with Varimax rotation was conducted with the 160 respondents' ratings for the 20-item acculturation scale. An initial exploratory factor analysis yielded six factors with eigenvalues exceeding unity, explaining $58.75 \%$ of the total variance. Application of the Scree Test, as illustrated in Figure 1, indicated that two factors appeared to warrant rotation using a Varimax rotation procedure. A two-factor solution was found in which Factor 1 and Factor 2 accounted for 14.81 and $11.83 \%$ of variance respectively.

As shown in Table 2, all eight items pertaining to the minority cultural elements had Factor 1 loadings of less than 0.30 and Factor 2 loadings greater than 0.30 . All 10 items pertaining to enjoyment of typical Brazilian culture loaded significantly $(>0.30$ ) onto Factor 1 , while loading

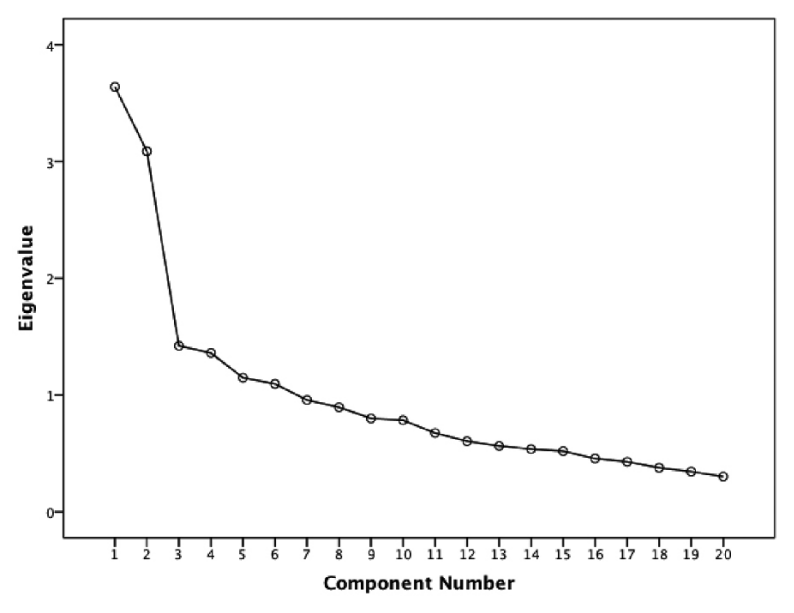

Figure 1 - Scree plot of eigenvalues minimally onto Factor $2(<0.30)$.

Table 2 - Factor coefficients according to the two-factor solution

\begin{tabular}{lcc}
\hline Item topics & Factor 1 & Factor $\mathbf{2}$ \\
\hline 1. Minority cultural values being part of life. & -0.039 & 0.516 \\
2. Importance of celebrating holidays in the minority cultural way. & 0.027 & 0.370 \\
3. Importance of raising children with minority cultural values. & 0.032 & 0.528 \\
4. Feeling comfortable among minority people who don't speak Portuguese. & -0.064 & 0.602 \\
5. Being proud of one's minority cultural background. & 0.045 & 0.491 \\
6. Enjoying speaking minority language. & -0.077 & 0.657 \\
7. Enjoying radio programs in the minority language. & -0.196 & 0.493 \\
8. Enjoying eating typical minority food. & -0.088 & 0.295 \\
9. Finding minority people kind and generous. & 0.085 & 0.495 \\
10. Importance of one's children having friends of minority cultural background. & 0.068 & 0.198 \\
11. Importance of celebrating holidays in the typical Brazilian way. & 0.328 & -0.054 \\
12. Typical Brazilian values being part of life. & 0.462 & 0.128 \\
13. Feeling comfortable among typical Brazilians who don't speak one's & 0.465 & -0.151 \\
nonnative language. & & \\
14. Importance of raising children with typical Brazilian values. & 0.631 & 0.004 \\
15. Being proud of one's typical Brazilian background. & 0.601 & -0.178 \\
16. Finding typical Brazilian people kind and generous? & 0.418 & 0.181 \\
17. Enjoying typical Brazilian TV programs. & 0.592 & 0.065 \\
18. Enjoying speaking Portuguese. & 0.596 & -0.233 \\
19. Enjoying eating typical Brazilian food. & 0.597 & 0.002 \\
20. Importance of one's children having typical Brazilian friends. & 0.469 & 0.072 \\
\hline
\end{tabular}




\section{Reliability and validity}

Table 3 lists internal consistency and reliability data for the BS. The 10 items measuring affiliation with minority cultural characteristics yielded a Cronbach's alpha coefficient of 0.69 . The corresponding 10 items measuring involvement in typical Brazilian culture had an alpha coefficient of 0.78 . The overall Cronbach's alpha for all 20 items of the BS was 0.67 .
Analyses of correlations were also conducted for each set of items in combination with generational status. There was no significant correlation between generational status and the items related to minority cultural aspects $(r=-0.14 ; p=0.08)$. In contrast, there was a significant correlation between items related to typical Brazilian culture and the generation of research participants $(r=0.23, p=0.004)$.

Table 3 - Reliability data for the Bicultural Scale

\begin{tabular}{|c|c|c|c|c|}
\hline Item number & $\begin{array}{c}\text { Scale mean if item } \\
\text { deleted }\end{array}$ & $\begin{array}{c}\text { Scale variance if item } \\
\text { deleted }\end{array}$ & $\begin{array}{c}\text { Corrected item-total } \\
\text { correlation }\end{array}$ & $\begin{array}{c}\text { Cronbach's alpha if } \\
\text { item deleted }\end{array}$ \\
\hline 1 & 39.86 & 36.88 & 0.25 & 0.66 \\
\hline 2 & 40.33 & 36.29 & 0.24 & 0.66 \\
\hline 3 & 39.81 & 35.64 & 0.34 & 0.65 \\
\hline 4 & 40.01 & 35.75 & 0.26 & 0.66 \\
\hline 5 & 39.54 & 36.16 & 0.32 & 0.66 \\
\hline 6 & 39.66 & 36.10 & 0.31 & 0.66 \\
\hline 7 & 40.16 & 36.95 & 0.17 & 0.67 \\
\hline 8 & 39.38 & 38.54 & 0.10 & 0.67 \\
\hline 9 & 39.95 & 35.67 & 0.34 & 0.65 \\
\hline 10 & 39.55 & 33.75 & 0.17 & 0.69 \\
\hline 11 & 40.24 & 37.40 & 0.17 & 0.67 \\
\hline 12 & 40.09 & 36.01 & 0.34 & 0.65 \\
\hline 13 & 40.31 & 36.79 & 0.19 & 0.67 \\
\hline 14 & 39.96 & 35.91 & 0.35 & 0.65 \\
\hline 15 & 39.83 & 37.47 & 0.19 & 0.67 \\
\hline 16 & 39.92 & 36.36 & 0.34 & 0.66 \\
\hline 17 & 40.13 & 35.58 & 0.34 & 0.65 \\
\hline 18 & 39.89 & 37.43 & 0.17 & 0.67 \\
\hline 19 & 39.83 & 36.04 & 0.35 & 0.65 \\
\hline 20 & 39.66 & 36.62 & 0.31 & 0.66 \\
\hline
\end{tabular}

\section{Pearson product-moment correlation}

The analysis of correlations computed between individual scores on each subscale for the entire sample, based on summation of unit-weighted items, yielded non-significant figures $(r=-0.47 ; p=0.56)$. The results of analyses of correlation between the scores of both subscales (related to the minority and typical Brazilian cultural affiliations) for each group are shown in Table 4.

\section{Test-retest analysis}

Twenty research participants were retested 1 week later. A Pearson correlation analysis of test-retest reliability yielded a coefficient of 0.8 between both sets of scores for these volunteers. Furthermore, only 4 of the 20 items investigated did not achieve significant correlations between scores generated in the two sets of interviews conducted 1 week apart. All items that did not

Table 4 - Comparative analysis between the minority and majority subscales in each group ( $n=40$ per group)

\begin{tabular}{|c|c|c|c|c|c|c|c|c|}
\hline & \multicolumn{2}{|c|}{ Minority subscale } & \multicolumn{2}{|c|}{ Majority subscale } & \multicolumn{2}{|c|}{ Correlations } & \multicolumn{2}{|c|}{ Paired t Test } \\
\hline & Mean & SD & Mean & SD & $\mathbf{r}$ & p-value & $\mathbf{t}$ & p-value \\
\hline German & 22.05 & 4.07 & 20.93 & 4.23 & 0.42 & 0.01 & 1.59 & 0.12 \\
\hline Italians & 19.45 & 5.18 & 19.58 & 4.77 & -0.29 & 0.07 & -0.99 & 0.92 \\
\hline Japanese & 21.45 & 4.28 & 19.85 & 5.20 & -0.96 & 0.56 & 1.44 & 0.16 \\
\hline Polish & 24.25 & 4.22 & 20.48 & 3.00 & -3.56 & 0.02 & 3.99 & 0.00 \\
\hline
\end{tabular}

$\mathrm{SD}=$ standard deviation. 
achieve correlations were related to the typical Brazilian culture (questions 11, 15, 16 and 19).

\section{Ease of use results}

The mean time required to complete the questionnaire was 7.4 minutes $(S D=5.4$; range $=34$ [35-1]). The majority of research participants $(44.4 \%)$ found it very easy to complete the BS, $43.8 \%$ found it reasonable easy, while 10.6 and $1.3 \%$ found it reasonably difficult and very difficult respectively.

\section{Discussion}

The demographic findings of this study reveal a typical research participant who is a middle-aged woman representing a third generation of immigrants in southern Brazil. The generational status of most of the participants is therefore consistent with the pattern of immigration arrivals to southern Brazil in the late 19th and early 20th centuries.

The Portuguese version of the BS was found to be highly reliable as an assessment tool, given the significant Cronbach's coefficients for both sets of items, measuring affiliation to minority and typical Brazilian culture. The overall alpha for the entire 20-item questionnaire was also satisfactory. Furthermore, the majority of scores did not change significantly over the course of 1 week. These findings confirmed further the reliability of the Portuguese version of the BS as a valid research tool for assessment of biculturality in Brazil. The majority of participants found it very easy or reasonably easy to complete the BS, with a mean time of less than 10 minutes to accomplish the task. Therefore, the BS represents a reliable and easy-to-use research tool for assessing people from different cultural backgrounds in Brazil.

Two factors accounted for most of the variance of the Portuguese version of the BS, which confirms its consistency with the concept of biculturality. The bifactor solution for the Portuguese version of the BS is indeed in agreement with the results of the original validation study of the BS, in which a "two-factor solution appeared most tenable" (Cortes et al.,6 page 714). The results of the factor analysis are in line with the original bidimensional concept and design of the BS, given that items related to the ancestral or minority culture loaded on the first dimension, whereas items related to the local majoritarian culture loaded on the second factor.

Endorsement of items related to the typical Brazilian culture was significantly correlated with generational status. The more distant the participant's generation was from original immigrants, the stronger their affiliation with typical Brazilian cultural characteristics. Considering that the majority of the sample were members of the third generation, it is possible that participants may have undergone attenuation of their ancestral cultural influences transgenerationally. Additionally, the initial generations of immigrants from Germany and Italy were not known for manifesting intense nationalistic ideas, given that the unification of Germany and Italy only occurred later in the 19th century, while Poland regained its independence in 1918. Another factor that may have played a role in suppressing strong sentiments towards the ancestral culture has to do with the political rejection and public censure of connections to and sympathies for Germany in Brazil during and following World War II. For similar political reasons, immigrants from Japan and Italy also suffered restrictions in Brazil in the post-war period. In 1942, Brazilian President Getúlio Vargas passed a decree enabling the Brazilian State to confiscate assets belonging to German, Japanese and Italian immigrants, who were dubbed "Servants of the Axis" (or "Súditos do Eixo" in Portuguese), as a form of compensation for losses occasioned by World War II. ${ }^{22}$

Acculturative stress that descendants of immigrants may have endured could possibly be associated with an increased risk of physical and mental disorders. The association between acculturation and parameters of health and wellbeing has been investigated in Brazil among descendants of Japanese, ${ }^{23-25}$ German, ${ }^{26}$ and Italian ${ }^{27-29}$ immigrants. Future studies of these intersections to be conducted in Brazil should also take into account biculturality as a possible moderating factor of exposure to risk of mental and physical disorders.

Certain limitations may also apply to the current study. Given that the research participants were recruited at outpatient healthcare facilities, the sample investigated in this study may not be fully representative of the greater population of the larger community of individuals living in Brazil. It is plausible to infer that various conditions of physical and mental health may have contributed to participants' perceptions and to their responses to the questionnaire. Given that ease of use was deemed a central aspect for investigation in this study, the authors chose not to request research participants to complete additional questionnaires or research forms, which could have biased this parameter of investigation and generated a less favorable impression of the process involved in the completion of the BS. One disadvantage of this approach was that convergent validity could not be appraised. Finally, there was an overrepresentation of female participants, which may have skewed response parameters. Additional studies with larger sample sizes and involving different communities of descendants of 
immigrants in other regions in Brazil are needed in order to confirm further the findings presented in this study.

\section{Conclusion}

The results of this study indicate that the Portuguese version of the BS is a valid, reliable and convenient assessment tool, which can be used as a research instrument to investigate biculturality in descendants of immigrants in southern Brazil. Supplementary studies are needed to test the Portuguese version of the BS in conjunction with additional research tools, particularly health-related measures, in order to further explore the usefulness of this research tool in a broader scenario.

\section{References}

1. Instituto Brasileiro de Geografia e Estatística (IBGE). Brasil: 500 anos de povoamento [Internet]. 2000 [cited 2016 Mar 28]. memoria.ibge.gov.br/publicacoes/brasil-500-anos-depovoamento.html

2. Carvalho-Silva DR, Santos FR, Rocha J, Pena SD. The phylogeography of Brazilian Y-chromosome lineages. Am J Hum Genet. 2001;68:281-6.

3. Schwarcz L. O espetáculo das raças: cientistas, instituições e questão racial no Brasil, 1870-1930. São Paulo: Companhia de Letras; 2002.

4. Levy M. [The role of international migration on the evolution of the Brazilian population (1872 to 1972)]. Rev Saude Publica. 1974;Suppl:49-90.

5. Social Science Research Council. Acculturation: an exploratory formulation. Am Anthropol. 1954;56:973-1000.

6. Cortes DE, Rogler LH, Malgady RG. Biculturality among Puerto Rican adults in the United States. Am J Community Psychol. 1994;22:707-21.

7. Thomson MD, Hoffman-Goetz L. Defining and measuring acculturation: a systematic review of public health studies with Hispanic populations in the United States. Soc Sci Med. 2009;69:983-91.

8. Ogilvie LD, Burgess-Pinto E, Caufield C. Challenges and approaches to newcomer health research. J Transcult Nurs. 2008; 19:64-73.

9. Kirmayer LJ, Narasiah L, Munoz M, Rashid M, Ryder AG, Guzder J, et al. Common mental health problems in immigrants and refugees: general approach in primary care. CMAJ. 2011;183:E959-67.

10. Mirsky J. Mental health implications of migration: a review of mental health community studies on Russian-speaking immigrants in Israel. Soc Psychiatry Psychiatr Epidemiol. 2009;44:179-87.

11. Bourque $F$, van der Ven $E$, Fusar-Poli $P$, Malla A. Immigration, social environment and onset of psychotic disorders. Curr Pharm Des. 2012;18:518-26.

12. Rogler LH, Cortes DE, Malgady RG. Acculturation and mental health status among Hispanics. Convergence and new directions for research. Am Psychol. 1991;46:585-97.

13. Padilla A. Acculturation and stress among immigrants and later generation individuals. In: Frick $D$, editor. The quality of urban life: social, psychological, and physical conditions. Berlin: Walter de Gruyter; 1987. p. 101-20.

14. Cortes D, Deren S, Andia J, Colon H, Robles R, Kang SY. The use of the Puerto Rican biculturality scale with Puerto Rican drug users in New Yorkand Puerto Rico. J Psychoactive Drugs. 2003;35:197-207.

15. Kang SY, Deren S, Mino M, Cortes DE. Biculturality and HIV-risk behaviors among Puerto Rican drug users in New York City. Subst Use Misuse. 2009;44:578-92.

16. Betancourt H, Lopez SR. The study of culture, ethnicity, and race in American psychology. Am Psychol. 1993;48:629-37.

17. Guillemin F, Bombardier C, Beaton D. Cross-cultural adaptation of health-related quality of life measures: literature review and proposed guidelines. J Clin Epidemiol. 1993;46:1417-32.

18. Ferraz MB. Cross cultural adaptation of questionnaires: what is it and when should it be performed? J Rheumatol. 1997;24:2066-8.

19. Mezzich JE, Ruiperez MA, Yoon G, Liu J, Zapata-Vega MI. Measuring cultural identity: validation of a modified Cortes, Rogler and Malgady Bicultural Scale in three ethnic groups in New York. Cult Med Psychiatry. 2009;33:451-72.

20. Matin G, Sabogal F, Matin BV, Otero-Sabogal R, Perez-Stable EJ. Development of a short acculturation scale for Hispanics. Hisp J Behav Sci. 1987;9:183-205.

21. Padilla A. The role of cultural awareness and ethnic loyalty in acculturation. In: Padilla AM, editor. Acculturation: theory, models, and some new findings. Boulder: Westview; 1980. p. 47-84.

22. Brasil, Camara do Deputados. Segunda Guerra Mundial: os bens confiscados e jamais devolvidos - Bloco 3 [ Internet]. 2011. www2.camara.leg.br/camaranoticias/ radio/materias/REPORTAGEM-ESPECIAL/405455-SEGUNDAGUERRA-MUNDIAL--OS-BENS-CONFISCADOS-E-JAMAISDEVOLVIDOS-\%2810\%2756\%27\%27\%29.html

23. Hiramatsu DA, Franco LJ, Tomita NE. [Influence of acculturation on self-perceived oral health among Japanese-Brazilian elderly]. Cad Saude Publica. 2006;22:2441-8.

24. Franco LJ. Diabetes in Japanese-Brazilians--influence of the acculturation process. Diabetes Res Clin Pract. 1996;34:S51-7.

25. Geloneze B, Yamanaka A. [One hundred years of Japanese immigration in Brazil: socio-metabolic lessons]. Arq Bras Endocrinol Metabol. 2008;52:3-5.

26. Kamphoefner W, Bjerg M. [Who went south? The choice of destination among German immigrants in the 19th century]. Estud Migr Latinoam. 1999;14:23-47.

27. Cimadon HM, Geremia R, Pellanda LC. Dietary habits and risk factors for atherosclerosis in students from Bento Goncalves (state of Rio Grande do Sul). Arq Bras Cardiol. 2010;95:166-72.

28. Lisot CL, Silla LM. [Screening for hemoglobinopathies in blood donors from Caxias do Sul, Rio Grande do Sul, Brazil: prevalence in an Italian colony]. Cad Saude Publica. 2004;20:1595-601.

29. Xavier FM, Ferraza MP, Argimon I, Trentini CM, Poyares D, Bertollucci PH, et al. The DSM-IV 'minor depression' disorder in the oldest-old: prevalence rate, sleep patterns, memory function and quality of life in elderly people of Italian descent in Southern Brazil. Int J Geriatr Psychiatry. 2002;17:107-16.

\section{Correspondence:}

Carlos Zubaran

Department of Psychiatry, Hornsby Hospital

Hornsby, NSW 2077, Australia

E-mail: zubaran_jr@yahoo.com 